\title{
Assessment of benthic and coral community structure in an inshore reef in Balok, Pahang, Malaysia
}

\author{
MUHAMMAD FAIZ MOHD HANAPIAH ${ }^{1,2, \vartheta}$, SHAHBUDIN SAAD ${ }^{2}$, ZUHAIRI AHMAD ${ }^{2}$, \\ MUHAMMAD HAMIZAN YUSOF ${ }^{\mathbf{1}}$, MOHD FIKRI AKMAL KHODZORI \\ ${ }^{1}$ Department of Biotechnology, Kulliyyah of Science, International Islamic University Malaysia. Jalan Sultan Ahmad Shah, Bandar Indera Mahkota, \\ 25200 Kuantan, Pahang, Malaysia. Tel.: +6095716400, `email: faizhanapiah@gmail.com \\ ${ }^{2}$ Department of Marine Science, Kulliyyah of Science, International Islamic University Malaysia. Jalan Sultan Ahmad Shah, Bandar Indera Mahkota, \\ 25200 Kuantan, Pahang, Malaysia
}

Manuscript received: 11 February 2019. Revision accepted: 26 February 2019

\begin{abstract}
Hanapiah MFM, Saad S, Ahmad Z, Yusof MH, Khodzori MFA. Assessment of benthic and coral community structure in an inshore reef in Balok, Pahang, Malaysia. Biodiversitas 20: 872-877. Inshore water reef closer to human activities are often neglected since they are not protected by marine park management. Little is known on how this reef responses to challenging environment in terms of abundance, diversity and benthic community composition. This study provides a quantitative assessment on the benthic community composition at 5 reef sites in Balok, Pahang, Malaysia and observed the ecological adaptation in the reef community towards turbid water environment. Balok reef has $39 \%$ overall coral cover with very low macroalgae abundance (4\%). A total of 28 coral genera from 12 families have been recorded with Porites the most dominant genus in the coral assemblages. Most reef sites in Balok are categorized under conservation class 1 (CC1), which indicated that resilient and survival of the reef rely on stress-tolerators taxa. The data presented here showed that Balok reef is highly resilient towards constant exposure to high sedimentation and wave action.
\end{abstract}

Keywords: Balok, coral community, inshore reef

\section{INTRODUCTION}

Inshore reefs are often subjected to anthropogenic stressors due to proximity with highly developed coastal areas. The effects of coastal development in shaping benthic composition, coral distribution and diversity are well documented for the past decades (Browne et al. 2010; Pandolfi et al. 2003; Guest et al. 2016). Land-based activities were reported to increase sedimentation and reduce light availability which is vital for coral growth and survival (Fabricius et al. 2005; Ganase et al. 2016). Apart from that, pollution and nutrient discharge from the nearby river which transport pollution and nutrient could further degrade water quality in the inshore reef area. Therefore, the inshore reef is said to be vulnerable to ecological changes and assumed to be low in percentage covers and diversity (McCook et al. 1999). Balok reef is a unique, untouched and pristine reef. This patchy platform reef was only discovered by local divers less than a decade ago. To date, there has been less documented study available for this reef. Rani et al. (2016) have reported recruitment densities and coral community structure for this reef. Therefore, more detail analysis of the benthic composition interaction is needed for conservation consideration from the authority.

Previous reports on coral reefs distribution indicated shifting baseline pattern from coral dominance to macroalgae dominance in the area closer to human disturbance (Bonaldo and Hay 2014; Brown et al. 2017).
This phase shift has been driven by nutrient enrichment that promotes macroalgae growth (Brown et al. 2017). Eventually, coral may lose from the stiff competition of space and ultimately being outgrown by this faster-growing biota. These impacts could be mitigated with the existence of key herbivore species in the reef's ecosystem as suggested by Hughes et al. (2007). However, the constant removal of these key herbivore species through overfishing in certain reefs has accelerated this whole phase shift process. Besides that, sedimentation could directly bring negative impact on coral growth and distribution. Harborne et al. (2017) has reported the impact of suspended sediment on coral by smothering the polyps, decreasing photosynthetic activities as well as negatively influence recruitment, growth and survival rates

Nevertheless, some reefs managed to thrive in a challenging environment and undergone certain ecological adaptations. For instance, in the turbid reef located on inner central of GBR, coral communities were found to be diverse and distinctive (Fabricius et al. 2005; Sweatman et al. 2007) and possess a high degree of long-term community resilience (Perry et al. 2009). Recent evidence indicated that reefs response towards environmental changes by undergoing a major transition in the morphology of coral community structure. Guest et al. (2016) suggested that coral community structure may shift towards morphology which can tolerate new environmental condition. Branching coral such as Acropora which sensitive towards sedimentation and nutrient may shift towards more stress-tolerant taxa with massive 
morphologies such as Porites (Darling et al. 2013; McClanahan 2014). Nonetheless, stress-tolerant taxa have slow growth rate and thus directly impact on these types of coral could jeopardize the whole reef community structure. Therefore, conservation planning and coral reef protection are still important although these stress-tolerators can withstand turbid water. Our objectives were to (i) quantitatively assess the benthic composition and coral genera diversity in Balok reef and (ii) to investigate ecological adaptation in the reef community in a turbid water environment

\section{MATERIALS AND METHODS}

\section{Study area}

Balok reef is located about 4.8 nautical miles from Balok Beach, Kuantan, Pahang, Malaysia. This platform reef has an average depth of $8 \mathrm{~m}$ to $15 \mathrm{~m}$ depending on tides. Most of the fishing activities in this area involve the use of fish trap and angling fishery. Balok reef is moderately turbid due to suspended sediment with underwater visibility ranging from $5 \mathrm{~m}$ to $10 \mathrm{~m}$ depending on the tidal and current patterns (personal observation). Due to its proximity with the mainland, Balok reef is exposed to frequent high loads of suspended sediments due to rapid coastal development in Kuantan such as the construction of nearby Kuantan Port and Gebeng industrial area. This reef also experiences alternating seasonal monsoon, Northeast (NE) from November to March and Southwest (SW) from May to August which may influence variation in major winds and current directions. Such dynamic bimodal pattern could also contribute to the overall setting of the benthic composition. This study was conducted at five sites in Balok namely Angly 1 (ST1), Angly 2 (ST2), Angly 3 (ST3), Nemo reef (ST4) and Pelindung reef (ST5) as shown in Figure 1.

\section{Procedures}

\section{Benthic community composition}

To describe benthic community structure, a nondestructive method was applied by using Coral Video Transect (CVT) technique. Surveys were conducted by recording high-resolution video of four lines of $30 \mathrm{~m}$ transects at each reef site using an underwater camera (Olympus TG-2). For each site, 100 picture frames were selected randomly per each transect for analysis using Coral Point Count with Excel extension developed by Kohler and Gill (2006). Fifty random points were superimposed on each frame, giving a total of 100,000 points analyzed in this survey. Such high number of points were used to have a better taxonomic resolution for reefs with lower cover (Pante and Dunstan, 2012; Safuan et al., 2016). Coral was identified up until genus level by referring to Veron (2005) while other benthic structures were categorized following English et al. (1999). Coral biodiversity was analyzed using Shannon-Weiner diversity index. The equation is as follows:

$$
H^{\prime}=-\Sigma(\text { pi ln pi) }
$$

Where:

$\mathrm{P} i$ : the proportion cover of the $i$ th genera along the transect line.

H': was calculated based on the proportional cover of genera.

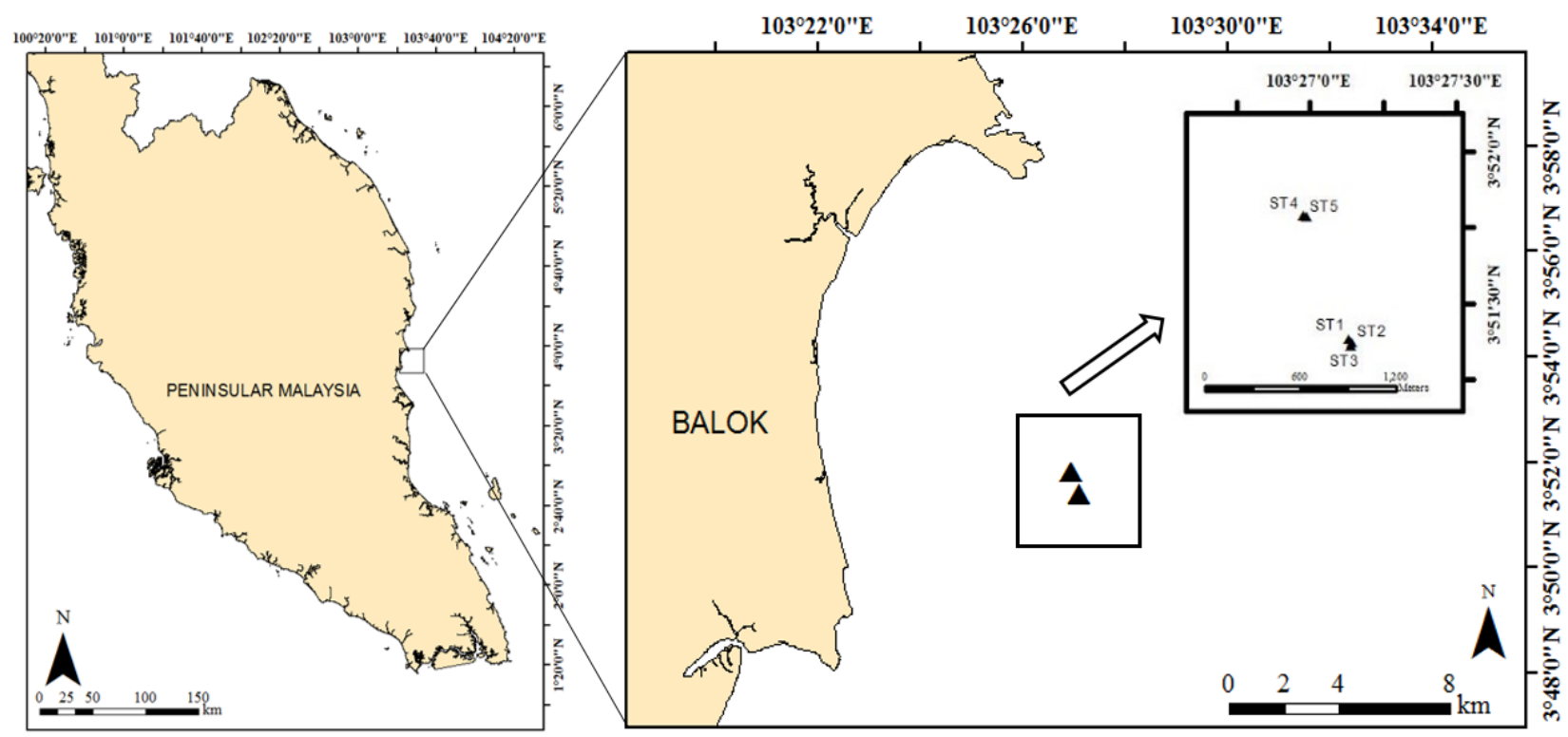

Figure 1. Location of study area in Balok reef, Kuantan, Pahang, Malaysia. Five sampling sites were selected, namely ST1

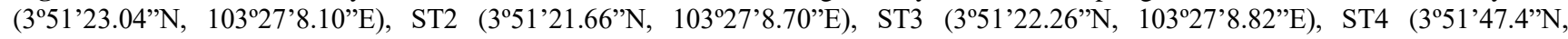
$\left.103^{\circ} 26^{\prime} 58.86^{\prime \prime} \mathrm{E}\right)$ and ST5 (351'47.10’'N, 103²6'59.64”'E). 


\section{Coral conservation class analysis}

The r-K-S ternary diagram was plotted to describe ecological adaptation for coral reef in Balok following Edinger and Risk (2000) based on the total cover of various coral morphology categories. This ternary diagram evaluates the inclination of coral community composition based on the relative abundance of three key coral morphology categories; ruderal (r), competitors (K) and stress-tolerators $(\mathrm{S})$. In this classification, four types of conservation classes (CC) were assigned: with reefs dominated by massive and submassive are considered as stress-tolerators (CC1); foliose or branching non Acropora are categorized as competitors (CC2); Acropora corals are known as ruderal (CC3) and mixed composition of these three categories (CC4).

\section{Statistical analysis}

Benthic community structure in Balok reef was compared using SPSS Statistics for Windows, version 22 (IBM Corp., New York). One-way analysis of variance (ANOVA) was used to compare percentage cover of each benthic structure between sites. Post hoc Tukey HSD test was applied to determine significant differences within categories. Spearman's Rank (Orders) correlation was used to demonstrate the relationship between each benthic community component.

\section{RESULTS AND DISCUSSION}

\section{Coral community structure}

The mean $(n=20)$ for live coral cover in Balok reef was $39 \% \pm 3.77$ as shown in Figure 2. Abiotic categories (sand and rock) contribute $29.4 \% \pm 1.95$ while invertebrates comprise $26.4 \% \pm 4.35$ of overall benthic structure. Coral $(\mathrm{F}=31.83, \mathrm{df}=4, \rho<0.01)$ and invertebrate $(\mathrm{F}=63.75$, df $=4, \rho<0.01)$ cover varied significantly among sites with ST3 and ST5 recorded the highest coral cover $(50 \%)$ while low coral cover was observed in ST4 (13.7\%) as shown in Figure 2. Spearman's correlation indicated negative correlation between live coral cover with percentage cover of sea anemone $(\mathrm{r}=-$ $0.74, \rho<0.01)$, sea urchin $(r=-0.5, \rho<0.05)$ and CCA ( $r$ $=-0.48, \rho<0.05)$. Despite having a fair coral cover, Balok reef has low dead coral cover $(1 \% \pm 0.24)$. Hence, it may be considered as healthy reef.

The present study has recorded 12 families and 28 genera from five reef sites. Reef sites were mainly dominated by massive Porites (64.6\%) followed by Acropora (16.8\%), Montipora (11.72\%) and Pocillopora $(1 \%)$. Other coral genera were less abundant (as shown in Table 1) and occasionally occurred in transects surveyed. The overall genera diversity in Balok reef is $\mathrm{H}^{\prime}=1.18$ and ST5 recorded the highest $\left(H^{\prime}=1.22\right)$ while ST2 recorded the lowest $\left(\mathrm{H}^{\prime}=0.82\right)$.

\section{Coral conservation class}

Three out of five reef sites were categorized as Conservation Class1 $(\mathrm{CC}=1)$. ST2 and ST3 have more than $75 \%$ average of stress-tolerators cover while ST4 has slightly above $60 \%$ stress-tolerators. Stress tolerators taxa were mainly contributed by massive Porites. ST1 has a mixed abundance of coral morphology categories and classified as CC4 together with ST5 even though the later has just below $60 \%$ stress-tolerators abundance to fall under CC1.

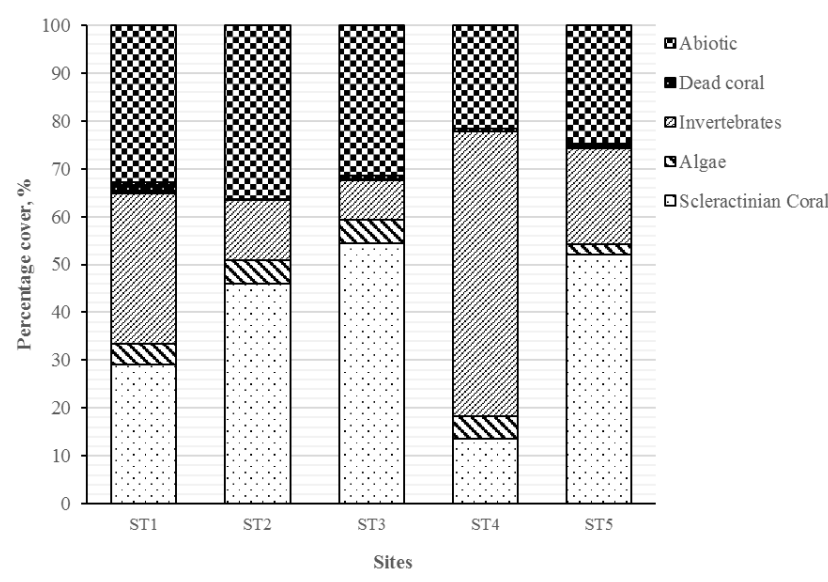

Figure 2. Benthic community structure distribution of each reef site in Balok reef, Kuantan, Malaysia

Table 1. Average percentage of coral genera in Balok reef, Kuantan, Malaysia

\begin{tabular}{|c|c|c|}
\hline Coral genera & Mean & SD \\
\hline Porites & $64.6=$ & \pm 19.55 \\
\hline Acropora & $16.8=$ & \pm 13.27 \\
\hline Montipora & $11.7=$ & \pm 17.51 \\
\hline Pocillopora & $1.0=$ & \pm 1.82 \\
\hline Turbinaria & $0.9=$ & \pm 1.52 \\
\hline Platygyra & $0.8=$ & \pm 2.09 \\
\hline Favites & $0.6=$ & \pm 1.28 \\
\hline Psammocora & $0.5=$ & \pm 0.82 \\
\hline Leptoseris & $0.4=$ & \pm 0.73 \\
\hline Cycloseris & $0.4=$ & \pm 1.45 \\
\hline Dipsastraea & $0.4=$ & \pm 0.74 \\
\hline Pachyseris & $0.3=$ & \pm 1.03 \\
\hline Lobophyllia & $0.3=$ & \pm 1.28 \\
\hline Pavona & $0.3=$ & \pm 0.68 \\
\hline Leptophyllon & $0.2=$ & \pm 0.54 \\
\hline Fungia & $0.2=$ & \pm 0.49 \\
\hline Stylopora & $0.1=$ & \pm 0.34 \\
\hline Oulastrea & $0.1=$ & \pm 0.25 \\
\hline Physogyra & $0.1=$ & \pm 0.3 \\
\hline Goniastrea & $0.1=$ & \pm 0.24 \\
\hline Symphyllia & $0.1=$ & \pm 0.22 \\
\hline Euphyllia & $0.1=$ & \pm 0.23 \\
\hline Pseudosiderastrea & $0.0=$ & \pm 0.16 \\
\hline Oulophyllia & $0.0=$ & \pm 0.13 \\
\hline Pectinia & $0.0=$ & \pm 0.15 \\
\hline Goniopora & $0.0=$ & \pm 0.06 \\
\hline Ctenactis & $0.0=$ & \pm 0.05 \\
\hline Tubastrea & $0.0=$ & \pm 0.02 \\
\hline
\end{tabular}




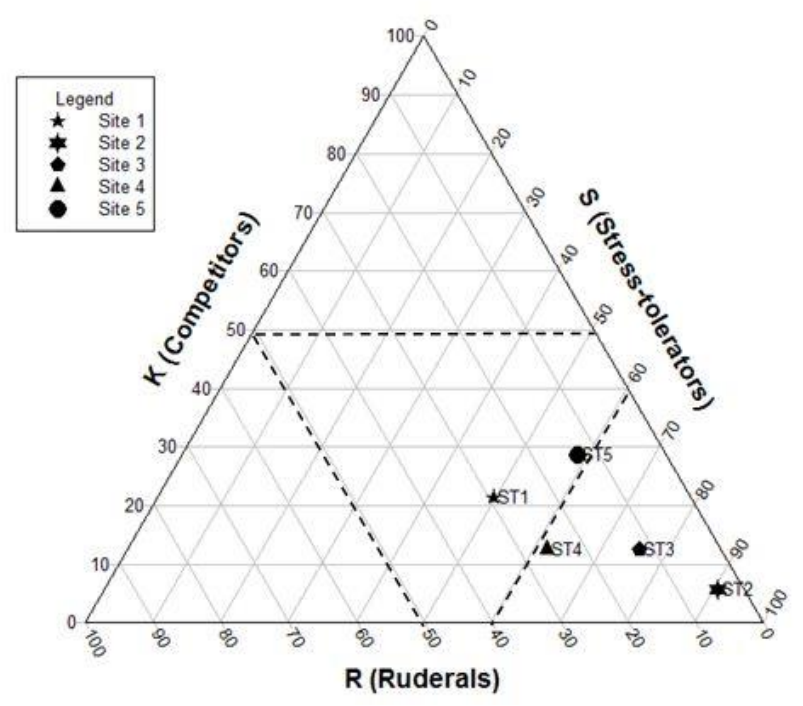

Figure 3. r-K-S ternary diagram which indicates coral conservation class score for 5 reef sites in Balok reef, Kuantan, Malaysia. Most of the reef sites dominated by stress-tolerators (ST2, ST3, and ST4) while ST1 and ST5 has mixed coral morphologies

\section{Discussion}

In the present study potential impacts from human activities were investigated on isolated, unprotected inshore turbid reef and how the present condition has to shape the benthic and coral composition. With an average of 39\% coral cover, Balok reef condition can be considered as 'fair' according to Chou et al. (1999). Some sites (ST3 and ST5) demonstrated slightly above $50 \%$ coral cover which considered as 'good' and this is comparable to coral condition reported in Tioman Island and Redang Island (Shahbudin et al. 2017). In fact, Balok reef has better coral cover compared to turbid reef in the west coast of Peninsular Malaysia within Sembilan Island Archipelago and Jarak Island as reported by Safuan et al. (2016).

Most of the coral cover was contributed by Porites, a massive genus which often dominated coral assemblages as it performs well towards thermal stress and sedimentation (Denis et al. 2017). It can be postulated that direct human impact was minimal in Balok reef since the dead coral cover was very low and there was no direct removal of coral colonies observed throughout the study. This could partly because of Balok reef located within Zone A (0-5 $\mathrm{nm})$ whereby reef destructive fishing such as trawling is strictly not allowed (Department of Fisheries, Malaysia 2018). In Malaysia, there is four types of fishing zone implemented by this Department of Fisheries according to the distance from the mainland (Zone A: 0-5nm; Zone B: 5-12 nm; C: $12-30 \mathrm{~nm}$ ). The occurrence of turf algae was also occasional, suggesting the present herbivore grazing is suffice in controlling macroalgae growth. Another probable explanation is that suspended sediment limit light penetration, and this may suppress macroalgae growth as suggested by (Guest et al. 2016).

Coral reef community in Balok may be subjected to pre-emptive effects in competition for space. As reefs assemblages mainly driven by slow-growing taxa in Porites, they can be easily outgrown by faster-growing biotas such as sea anemone and crustose coralline algae. This could explain the low coral cover pattern observed in ST4 whereby sea anemone assemblages (Heteractis magnifica) was very dominant in all transects. Lee et al. (2015) have also reported dense assemblages pattern of bulb tentacle sea anemone (Entacmea quadricolor) ranging from 16-76\% substratum cover at four sites in Hong Kong. Elsewhere, it has been discovered in the Red Sea that a single population of this invertebrate can spread out over several kilometers (Chadwick et al. 2008; Dixon et al. 2014) and up to $94 \%$ substratum cover was observed in North Solitary Island, Australia (Scott et al. 2011). The emergence of this invertebrate in ST4 was still unknown though it has been suggested population density of sea anemone was influenced by local nutrient level, habitat suitability and hydrodynamic regime (Hattori 2016; Scott et al. 2011).

Balok reef has low genera richness (28 genera) compared to clear water reefs in the east coast of Peninsular Malaysia such as Tioman Island (65 genera) and Redang Island (55 genera) as reported by Fikri Akmal (2016). High turbidity environment could be the main reason as most of the coral species are very sensitive towards this disturbance specifically high suspended sediment. Suspended sediment also has been reported to suppress coral species in various part of life stage (Jones et al. 2015). Therefore, the present condition only favors certain genus which can withstand the turbid environment. However, the overall genera diversity was comparable to study in the turbid water of middle reef, GBR which has low H' indices of 1.64 (Browne et al. 2010).

Most reef sites in Balok are categorized under conservation class 1 (CC1), which indicated that resilient and survival of the reef rely on stress-tolerators taxa, in this case, the massive Porites. Despite having relatively low growth rates with radial growth rates $1-2 \mathrm{~cm}_{\text {year }}^{-1}$ (Done et al. 1988), some area has enormous colonies size. This could indicate that Porites has been among the longest ever occupants in the reef. Stafford-Smith (1993) proposed that hemispherical and columnar morphology (most Porites sp.) can remove accumulated sediment efficiently. Colonies of competitors or fast-growing coral such as Turbinaria and Pocillopora are small in size, suggesting repetitive temporal shift occurred for this taxa throughout the years. Guest et al. (2016) have reported a temporal shift in coral taxa throughout 27 years of monitoring in Singapore. They suggested that coral community could experience a temporal shift in coral community composition depends on the changes in environmental stress such as high temperature and sedimentation.

Coverage of Acropora, which is the most abundant genus in most coral communities in shallow reef areas in Malaysia was relatively low in Balok. It is probable that high sedimentation suppresses the growth of this genus and influence its percentage cover. Safuan et al. (2016) also mentioned that Porites dominated highly turbid on the west coast of Peninsular Malaysia while clear-water reef in the east coast is dominated by Acropora and Montipora. It can 
also be suggested that coral community composition is influenced by the local hydrodynamic regime (Sheppard et al. 2009). Madin and Connolly (2006) suggested that branching morphologies of most Acropora species are vulnerable to breakage by high wave energy. Massive taxa such as Porites and Dipsastraea are more resistant and dominated area which experience constant wave action. Husaini (2016) reported that Balok reef has relatively high current speed $\left(0.7 \mathrm{~ms}^{-1}\right)$ and such high current speed does not favor complex morphological structure in Acropora. Elsewhere, Halid et al. (2016) discovered that in Tioman Island, Acropora was highly abundant in low current speed reef $\left(0.035 \mathrm{~ms}^{-1}\right)$ in Renggis Island while massive Dipsastraea dominated higher current speed $(0.172 \mathrm{~ms}-1)$ in Teduh Bay.

The findings presented here indicated that Balok reef remains resilient despite constant exposure to high sedimentation and wave action. Therefore, it is important to note that any further coastal development should consider the potential impacts on reef community since most sites are already within $\mathrm{CC} 1$ category. Being pristine and untouched reef, more studies should be carried out in the reef area such as water quality measurement, suspended sediment level and population density estimation of reef fish to assess reef health more broadly.

\section{ACKNOWLEDGEMENTS}

We would like to thank the Department of Marine Science, Kulliyyah of Science, International Islamic University Malaysia and INOCEM Research Centre, IIUM for technical assistance such as scuba diving equipment and logistic during field data collection. This project was funded by E-Science Grant (SF16-002-0071) under the Ministry of Energy, Science, Technology, Environment and Climate Change, Malaysia.

\section{REFERENCES}

Bonaldo RM, Hay ME. 2014. Seaweed-coral interactions: Variance in seaweed allelopathy, coral susceptibility, and potential effects on coral resilience. PLoS ONE 9 (1): e85786. DOI: 10.1371/journal.pone.0085786.

Brown KT, Bender-Champ D, Bryant DEP, Dove S, Hoegh-Guldberg O. 2017. Human activities influence benthic community structure and the composition of the coral-algal interactions in the central Maldives. J Exp Mar Biol Ecol 497: 33-40.

Browne NK, Smithers SG, Perry CT. 2010. Geomorphology and community structure of Middle Reef, central Great Barrier Reef, Australia: An inner-shelf turbid zone reef subject to episodic mortality events. Coral Reefs 29 (3): 683-689.

Chadwick N, Arvedlund M. 2005. Abundance of giant sea anemones and patterns of association with anemonefish in the northern red sea. $\mathbf{J}$ Mar Biol Assoc United Kingdom 85 (5): 1287-1292.

Chou LM, Wilkinson CR, Licuanan WRY, Alino P, Cheshire AC, Loo MGK, Tanjaitrong S, Sudara A, Ridzwan AR, Soekarno. 1994. Status of Coral Reefs in the ASEAN Region. Proceedings of the Third ASEAN-Australia Symposium on Living Coastal Resources. Australian Institute of Marine Science. Townsville, Australia.

Darling ES, McClanahan TR, \& Cote IM. 2010. Combined effects of two stressors on Kenyan coral reefs are additive or antagonistic, not synergistic. Conservation Letters 3 (2): 122-130.
Denis V, Ribas-Deulofeu L, Sturaro N, Kuo CY, Chen CA. 2017. A functional approach to the structural complexity of coral assemblages based on colony morphological features. Sci Rep 7 (1): 9849. DOI: 10.1038/s41598-017-10334-w.

Department of Fisheries Malaysia. 2018. Fishing Zonation in Peninsular Malaysia. Department of Fisheries Malaysia, Kuala Lumpur. www.dof.gov.my

Dixon AK, Needham D, Al-Horani FA, Chadwick NE. 2014. Microhabitat use and photoacclimation in the clownfish sea anemone Entacmaea quadricolor. J Mar Biol Assoc United Kingdom 94 (3): 473-480.

Done TJ, Osborne K, Navin KS. 1988. Recovery of Corals Post Ancaster: Progress and Prospects. In: Proceedings 6th International Coral Reef Symposium, 137-142. Townsville. [Australia]

Edinger EN, Risk MJ. 2000. Reef classification by coral morphology predicts coral reef conservation value. Biological Conservation 92 (1): 1-13.

Fabricius K, De'ath G, McCook L, Turak E, Williams DM. 2005. Changes in algal, coral and fish assemblages along water quality gradients on the inshore Great Barrier Reef. Mar Pollution Bulletin 51 (1-4): 384-398.

Ganase A, Bongaerts P, Visser PM, Dove SG. 2016. The effect of seasonal temperature extremes on sediment rejection in three scleractinian coral species. Coral Reefs 35 (1): 187-191.

Guest JR, Tun K, Low J, Verges A, Marzinelli EM, Campbell AH, Bauman AG, Feary DA, Chou LA, Steinberg PD. 2016. 27 years of benthic and coral community dynamics on turbid, highly urbanised reefs off Singapore. Sci Rep 6 (1): 36260.

Halid NH, Ahmad A, Kamarumtham K, Saad S, Khodzori MFA, Mohd HMF, Yusof MH. 2016. The effect of current on coral growth form in selected areas of Tioman Island, Pahang. Trans Sci Technol 3 (3): 393-402.

Harborne AR, Rogers A, Bozec YM, Mumby PJ. 2017. Multiple Stressors and the Functioning of Coral Reefs. Ann Rev Mar Sci 9 (1): 445-468.

Hattori A. 2006. Vertical and horizontal distribution patterns of the giant sea anemone Heteractis crispa with symbiotic anemonefish on a fringing coral reef. J Ethol 24 (1): 51-57.

Hughes TP, Baird AH, Bellwood DR, Card M, Connolly SR, Folke C, Grosberg R, Hoegh-Guldberg O, Jackson JBC, Kleypas J, Lough JM, Marshall P, Nystrom M, Palumbi SR, Pandolfi JM, Rosen B, Roughgarden J. 2003. Climate Change, Human Impacts, and the Resilience of Coral Reefs. Science 301 (5635): 929-933.

Hughes TP, Baird AH, Dinsdale EA, Moltschaniwskyj NA, Pratchett MS, Tanner JE, Willis BL. 2000. Supply-side ecology works both ways: The link between benthic adults, fecundity, and larval recruits. Ecology 81 (8): 2241-2249.

Hughes TP, Rodrigues MJ, Bellwood DR, Ceccarelli D, Hoegh-Guldberg O, McCook L, Moltschaniwskyj N, Pratchett MS, Willis BL. 2007. Phase shifts, herbivory, and the resilience of coral reefs to climate change. Curr Biol 17 (4): 360-365.

Husaini R. 2016. Spatio-temporal Variation of Scleractinian Coral Recruitment in Balok Coastal Waters and Bidong Island, Malaysia. [Dissertation]. International Islamic University Malaysia, Pahang. [Malaysia].

Jones R, Ricardo GF, Negri AP. 2015. Effects of sediments on the reproductive cycle of corals. Mar Poll Bull 100 (1): 13-33.

Kohler KE, Gill SM. 2006. Coral Point Count with Excel extensions (CPCe): A Visual Basic program for the determination of coral and substrate coverage using random point count methodology. Comput Geosci 32 (9): 1259-1269.

Lee KM, Xie JY, Sun Y, Kei K, Qiu JW. 2015. Four dense assemblages of the bulb-tentacle sea anemone Entacmaea quadricolor and associated clownfish in Hong Kong. J Mar Biol Assoc United Kingdom 95 (1): 63-68.

Lirman D. (2001). Competition between macroalgae and corals: effects of herbivore exclusion and increased algal biomass on coral survivorship and growth. Coral Reefs 19 (4): 392-399.

Madin JS, Baird AH, Dornelas M, Connolly SR. 2014. Mechanical vulnerability explains size-dependent mortality of reef corals. Ecol Lett 17 (8): 1008-1015.

McClanahan TR. 2014. Decadal coral community reassembly on an African fringing reef. Coral Reefs 33 (4): 939-950.

McCook LJ. (1999). Macroalgae, nutrients and phase shifts on coral reefs: scientific issues and management consequences for the Great Barrier Reef. Coral Reefs 18 (4): 357-367. 
Mohd KF. 2015. Diversity and distribution of corals with emphasis on morphological structures and phylogenetic analyses f Euphyllidae corals in Tioman, Redang and Payar Islands, Malaysia. [Dissertation] International Islamic University Malaysia, Pahang. [Malaysia].

Pandolfi JM, Bradbury RH, Sala E, Hughes TP, Bjorndal KA, Cooke RG, McArdle D, McClenachan L, Newman MJH, Paredes G, Warner RR, Jackson JBC. 2003. Global trajectories of the long-term decline of coral reef ecosystems. Science 301: 955-958

Pante E, Dustan P. 2012. Getting to the Point: Accuracy of Point Count in Monitoring Ecosystem Change. J Mar Biol 2012: 1-7.

Perry CT, Smithers SG, Johnson KG. 2009. Long-term coral community records from lugger Shoal on the terrigenous inner-shelf of the centra Great Barrier Reef, Australia. Coral Reefs 28 (4): 941-948.

Rani MH, Saad S, Khodzari MFA, Ramli R, Yusof MH. 2015. Scleractinian coral recruitment density in coastal water of Balok, Pahang, Malaysia. Jurnal Teknologi 25: 13-18.

Safuan M, Wee HB, Ibrahim YS, Idris I, Bachok Z. 2016. Current status on community structure of coral reefs around west coast of Peninsular Malaysia using coral video transect technique. J Sustain Sci Manag 11 (Special Issue 1): 107-117.
Scott A, Malcolm HA, Damiano C, Richardson DL. 2013. Long-term increases in abundance of anemonefish and their host sea anemones in an Australian marine protected area. Mar Freshw Res 62 (2): 187.

Shahbudin S, Akmal KF, Faris S, Normawaty MN, Mukai Y. 2017. Current status of coral reefs in Tioman Island, Peninsular Malaysia. Turkish J Zool 41: 294-305.

Sheppard CRC, Davy SK, Pilling GM. 2009. The Biology of Coral Reef. Oxford University Press, New York.

Stafford-Smith MG. (1993). Sediment-rejection efficiency of 22 Species of Australian Scleractinian Corals. Mar Biol 115: 229-243.

Sweatman H, Thompson A, Delean, S, Davidson L, Neale S. 2007. Status of nearshore reefs of the Great Barrier Reef 2007 MTSRF report. AIMS and Reef and Rainforest Research Centre, Townsville, Australia.

Veron JEN. 2000. Corals of the World. Volume 1-3. Australian Institute of Marine Science. Townsville, Australia.

Wooldridge S, Brodie J, Furnas M. 2006. Exposure of inner-shelf reefs to nutrient enriched runoff entering the Great Barrier Reef Lagoon: PostEuropean changes and the design of water quality targets. Mar Pollut Bull 52 (11): 1467-1479. 